\title{
ABLATIO FALCIFORMIS CONGENITA (RETINAL FOLD)
}

\author{
BY \\ Professor Dr. H. Weve \\ DIRECTOR, UNIVERSITY EYE CLINIC, UTRECHT
}

IN the Arch. f. Augenheilk., Bd. 109, of 1935, a description was given of a series of cases of congenital retinal folds and attention was drawn to their close relation to cases of pseudoglioma, caused by congenital retinal detachment. Therefore the name of " ablatio falciformis congenita" was chosen. Furthermore, it was shown that this congenital abnormality is in most cases familial and probably hereditary.

I pointed out that the congenital retinal folds as described can perhaps be imitated to a certain degree by inflammatory processes in childhood, but that on the other hand a number of peculiarities make it quite clear that this is not the case in our true cases of congenital folds.

At exactly the same time Ida Mann published in the Brit. Jl. of Ophthal., December, 1935, a very interesting paper dealing with a series of similar cases which this author could study anatomically. She found that in all the cases which have been examined microscopically, the whole of the retina (not only that in the fold) shows imperfect differentiation and this should put out of count any suggestion that the condition is at first a traumatic detachment or a localised inflammation. "We are dealing with a disturbance of growth of the whole of the inner layer of the optic cup at an early age."

Since my last communication I have had the opportunity of observing some more cases which sustain, like my former clinical and anatomical observations, this opinion. (See discussion, Nederlandsch Oogheelkundig Gezelschap, May 24, 1936, and Demonstration of the same Society, January 30, 1938.)

This will be abundantly clear from the following facts:(a) The typical form of congenital retinal fold is very often bilateral. If I include the cases of congenital total retinal detachment (" pseudo-glioma ") I find in 12 cases observed by myself 6 cases bilateral. From the 6 cases described by Ida Mann 3 are bilateral (in the other 3 cases nothing is said about the second eye). Further, the retinal fold was bilateral in the cases of Holm and in one of the cases of van Manen (not yet published), unilateral in the case of Salfner, in one of the cases of van Manen and in the case of de Vries-Ancona, although in the latter posterior polar cataract of the second eye was observed. 
Altogether in at least 11 of the 22 cases it was bilateral, that is, in 50 per cent.

(b) In all the bilateral cases observed the fold is symmetrical. This fact points very strongly to an abnormal development and against inflammatory origin.

(c) The abnormality is often familial. To this fact I first called attention in my above-mentioned paper. Since I paid special attention to this, I found it so frequently that the supposition is permitted that the same would hold for many of the other cases that were not studied from this point of view. (In this connection I might recall the frequency of arachnodactyly as a familial and hereditary disease. Before I drew attention to this it was not noticed although some cases were already described. Since then the number of familial cases has so increased that it almost seems the rule.)

Here are my own observations on the subject as described in previous communications :-

Family $A$.-Cases 1 and 2 are brothers. Case 3 is a child of the marriage of the son of the brother of the mother of cases 1 and 2 with the daughter of a sister of the same, i.e., first cousins.

Family B.-Cases 4 and 5 are sisters but, as it is doubtful whether case 5 belongs to this group of abnormal development, I prefer to leave case 5 out of consideration.

Family $C$.-Cases 6 and 7 are uniovular twins with symmetrical folds in all four eyes! This observation alone should prove sufficiently the non-inflammatory nature of the abnormality.

Family $D$.-Case 8 refers to a patient whose eye was enucleated nearly 20 years ago by the late Prof. Snellen. I had no opportunity of getting further information about the family.

Family E.-Cases 9 and 10 (to be described in this paper) are brother and sister. The parents are cousins. Case 11.-Another brother showed a forme fruste (examined at my request by Miss Ancona) but refused to come to the clinic for further examination.

Family $F$ (to be described in this paper).-Case 12 has a grandmother who shows a forme fruste.

This shows that familial occurrence was manifest in at least four of the five families I could study personally. In this connection I will also mention that in at least seven of my cases there is consanguinity of the parents.

(d) I must once more draw attention to the fact that the retinal fold shows in the great majority of the cases a prevalence for the temporo-inferior sector of the eye. If we include the horizontal and vertical meridian, this was the case in all the eyes seen by myself with the exception of only one case to be described in this paper. It was also so in the case of de Vries later anatomically described by Miss Ancona, in the case of Holm, in five of the 
eight eyes described by Miss Mann and in the case described by Tillema. In the second volume of Sir W. Stewart Duke-Elder's Text-Book of Ophthalmology I find in Fig. 1266 another beautiful example closely resembling most of my cases. On the contrary I know only very few cases with a fold in other meridians and these cases show other peculiarities that might perhaps justify their classification in a special category (see afterwards). (Both eyes of case 2 of Mann and her case 3, furthermore one of the cases of van Manen and one of my own observations.)

Although we are not yet able to give a satisfactory anatomical or embryological explanation of the above-mentioned fact, it seems in accordance with a congenital abnormality of development and in contradiction to an inflammatory explanation.

(e) Another fact that points strongly in the direction of a developmental abnormality is the frequent association with other typical developmental abnormalities of non-inflammatory origin. In many cases a persistent hyaloid artery is found, and also persistent pupillary membrane is frequent. Microphthalmos in a slight degree and circumscript congenital cataract occur. Furthermore, nystagmus seems to be constant in bilateral cases and frequent in unilateral.

$(f)$ Until now the condition has only been observed as a congenital one or in early childhood. It seems unlikely that the eye of the adult should never be able to respond in a similar way to an inflammation with cyclitic membrane, and as long as such cases cannot be proved to exist inflammatory origin of cases in early childhood is at least suspect.

Fig. 1 shows the condition found in an eye kindly lent me by Professor Emil de Grosz from Budapest. In this traumatic case something resembling the described abnormality is found but anatomical study shows that it is a simple case of cicatricial local detachment, caused by holes at the ora serrata and without abnormality of the retinal vessels (which cannot be seen in the picture). Short history of the case :-

Praep. Nr. 5872.-At the age of six perforation with a knife. Cicatrix adhaerens corneae et sclerae. Cataracta traumatica complicata. Atrophia bulbi. Hypotonia.

That inflammatory cases resembling strongly the ablatio falcif. cong. may exist nevertheless is made probable by the description of a case given in my first paper.

Tillema in his paper erroneously refers to this observation as to my " case 8." I did not give this case a number as in my opinion it did not belong to the "congenital" class.

(Tillema's conclusion that this case and his own prove an inflammatory origin and "Weve's original idea to be correct" needs further correction as I never advocated an inflammatory origin of the "Ablatio falciformis congenita" but only mentioned it while I discussed the different theoretical possibilities). 
Here I might also state that possibly even in this case ( $\mathrm{Nr} .2356$ ) that was not observed by me personally but many years ago by a provincial physician, the inflammation may have been secondary to a congenital abnormality. This, as Waardenburg pointed out in the discussion in the Dutch Ophthalmological Society (May, 1936), where Tillema read his paper, is by no means rare

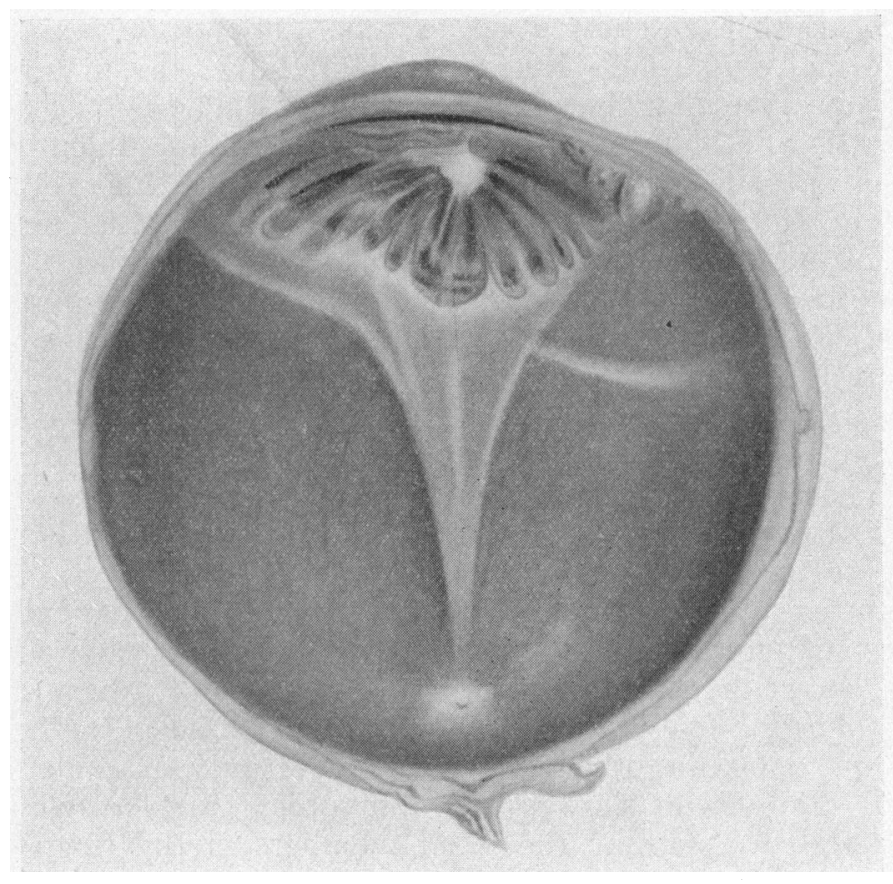

FiG. 1.

Pseudo ablatio falciformis of traumatic origin. (Praep. 5872.)

and could have happened, especially in Tillema's case. See also Carl Heyl, pages 16 and 17.

(g) As Miss Mann pointed out the whole of the retina shows, in the cases studied by her, imperfect differentiation, which should put out of court any suggestion that the condition is at first a traumatic detachment or a localised inflammation.

(h) The occurrence of the condition in the same family alternating with typical "pseudo-glioma" of the complete retinal detachment type strongly suggests the aetiological identity of both conditions.

As Cari Heyl points out in his recent book, "Ueber Retiniten unbekannten Ursprungs, 1937," we must abandon Leber's 
opinion about the inflammatory origin of this form of " pseudoglioma." In his opinion the great majority of the so-called pseudo-gliomata are congenital abnormalities.

Rintelen (Graefe's Archiv., 135, 1936) came to the same conclusion. The anatomical examination of the eye to be described in this communication also supports this opinion.

Here follows the description of a new case of congenital fold :

P.O., the patient, came in January, 1936, to our clinic from Vianen. Both eyes showed nystagmus. The right eye showed no abnormal condition. Refraction $\mathrm{Hm}$. 1.0D. From birth the parents observed that the eyesight was bad. The left eye shows slight microphthalmos with typical " ablatio falciformis." Skiascopically there was 3.0D. myopia. The retinal fold runs almost horizontally and is inserted partly on the posterior surface of the lens (Fig. $z$ ). The fundus shows the typical appearance of other cases with depigmentation and abnormal pigmentation at both sides of the fold. With the ophthalmoscope or the slit-lamp no persistent hyaloid artery can be found. Some very white spots (calcareous deposits?) on the peripheral parts of the ridge drew our attention. The optic disc shows the typical characteristics observed in nearly all of my cases, notably the ring of pigment. The vessels are extremely fine. It is almost impossible to distinguish arteries from veins.

The father and mother are cousins, German. The patient is the youngest of eight children. The eldest daughter, now aged 19 years, came at the age of six years to the Utrecht University Eye Clinic. The right eye was then extirpated for suspected glioma (see below). Of the other children I could only examine the 13 year old Hans, who showed slight myopia. Miss Ancona was kind enough to examine the other members of the family; she found three of them slightly myopic and further, only abnormalities in the left eye of the 16 year old Bob. Here the optic disc and the vessels emerging from it showed unmistakable signs of the abnormal condition in a slight degree. As the boy flatly refused a further examination, unfortunately I cannot give a picture or other details.

I was therefore the more interested in the study of the eye of the eldest girl, enucleated in 1923. At that time the anatomical examination was done in the laboratory of the pathological institute and only three slides were presented to our collection, all going through the optic nerve. Unfortunately the rest of the eye could not be recovered, but the slides of our collection allow, nevertheless, the diagnosis: pseudo-glioma of the congenital total detachment type.

I think it worth while to give a description of this case :

A.O. entered our clinic in 1923, aged six years. The parents 
assured us that the right eye was abnormal from birth, whilst the left eye seemed normal. The left eye was emmetropic and the vision was normal, although it was noticed that the retinal vessels were broad and made marked curves at the border of the optic disc and the papilla was not prominent. The right eye was completely blind. The pupil was displaced in a nasal and superior direction. At the lower pupillary margin strong synechiae post. were observed. The anatomical examination showed that the eccentricity of the pupil was combined with ectropion uveae and that both were caused by a mesoblastic tissue on the surface of the iris which also caused anterior synechiae in the upper periphery of the iris (obliteration of the angle of the anterior chamber). (Fig. 6.) No signs of recent inflammation or of glaucoma were

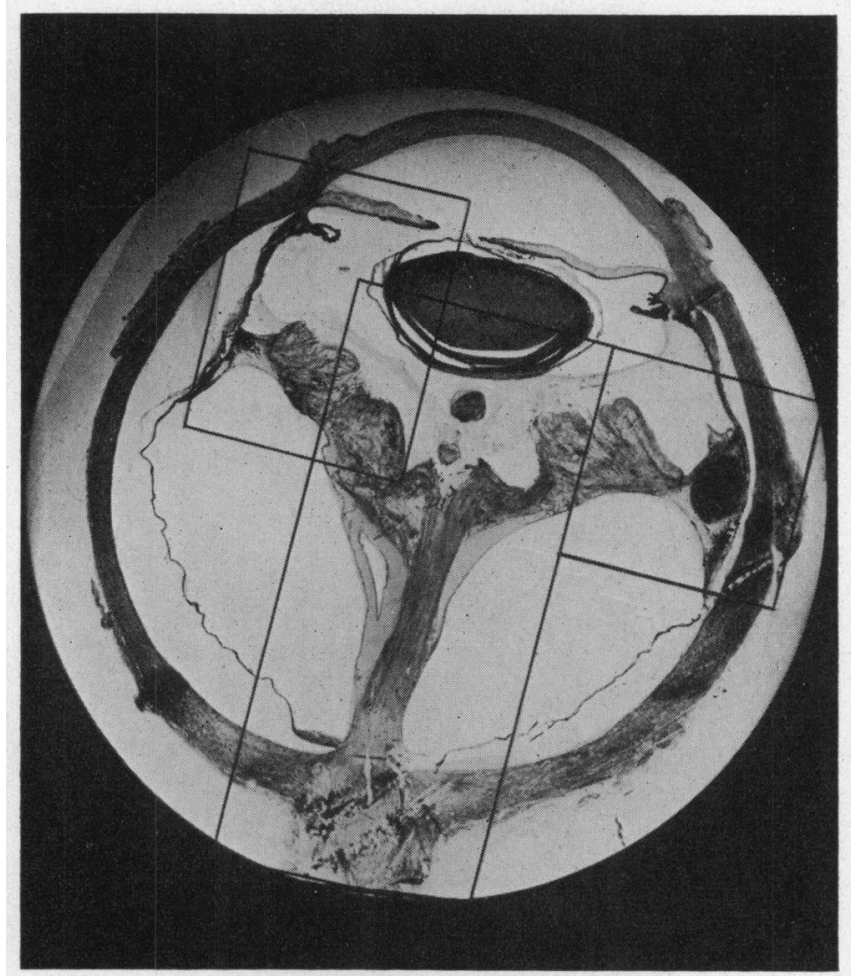

FIG. 3.

Photograph of section through the eye of Alida $O$. with congenital total detachment with indication of the parts reproduced in the pictures $4,5,6$. (The central part Fig. 4 is taken from a section very near to this one.) 


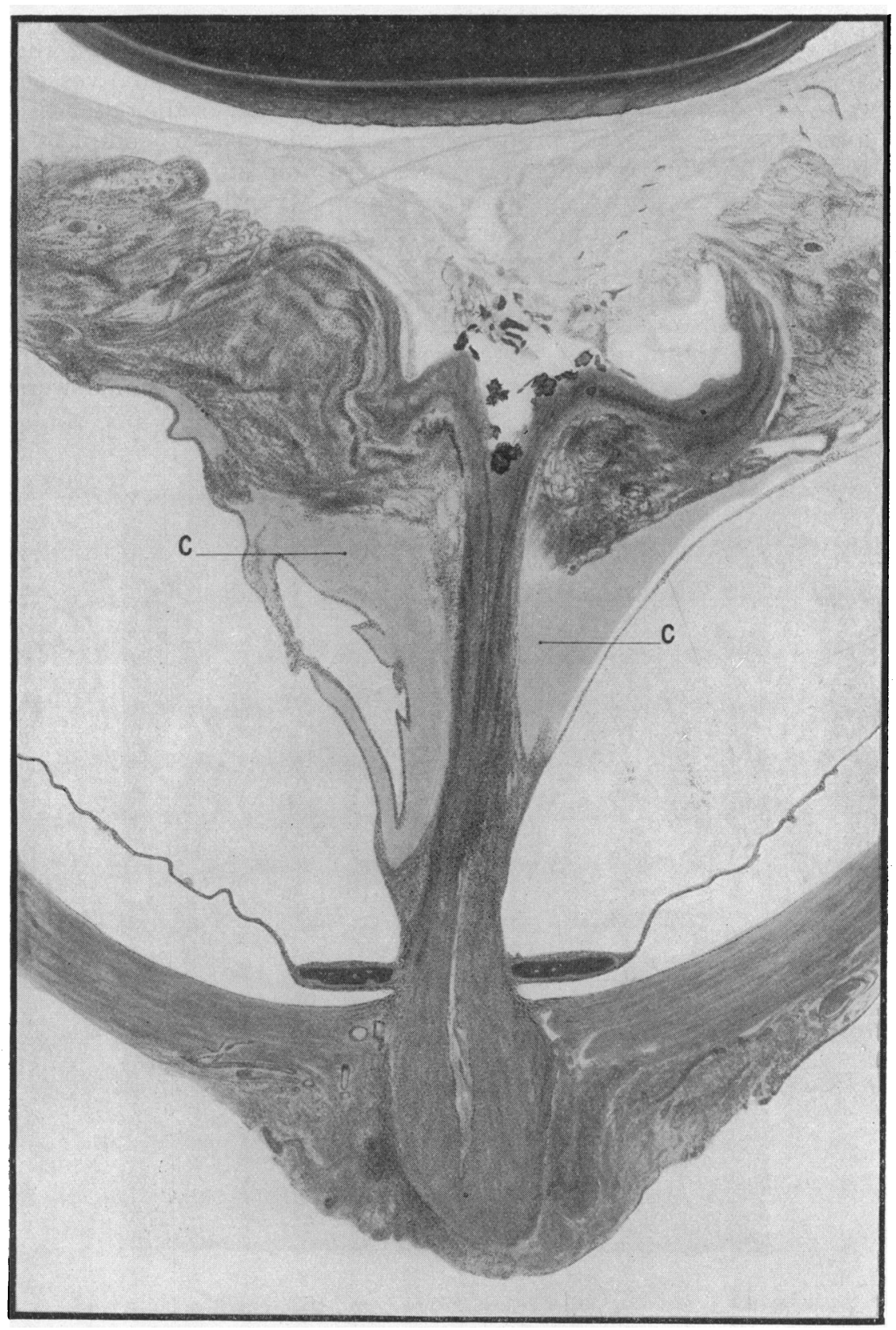

Fig. 4.

Central part of section through the right eye of the 6 years old Alida O. with pseudo-glioma $(c=c y s t s)$. See Fig. 3 . 
observed. Behind the lens a white cauliflower-like mass was observed with glimmering crystals. Through and between this mass here and there bloodvessels were visible. As this suggested a glioma the eye was enucleated. It was slightly microphthalmic. Dimensions in anatomical slides $19 \mathrm{~mm}$. long and $18 \frac{1}{2} \mathrm{~mm}$. broad.

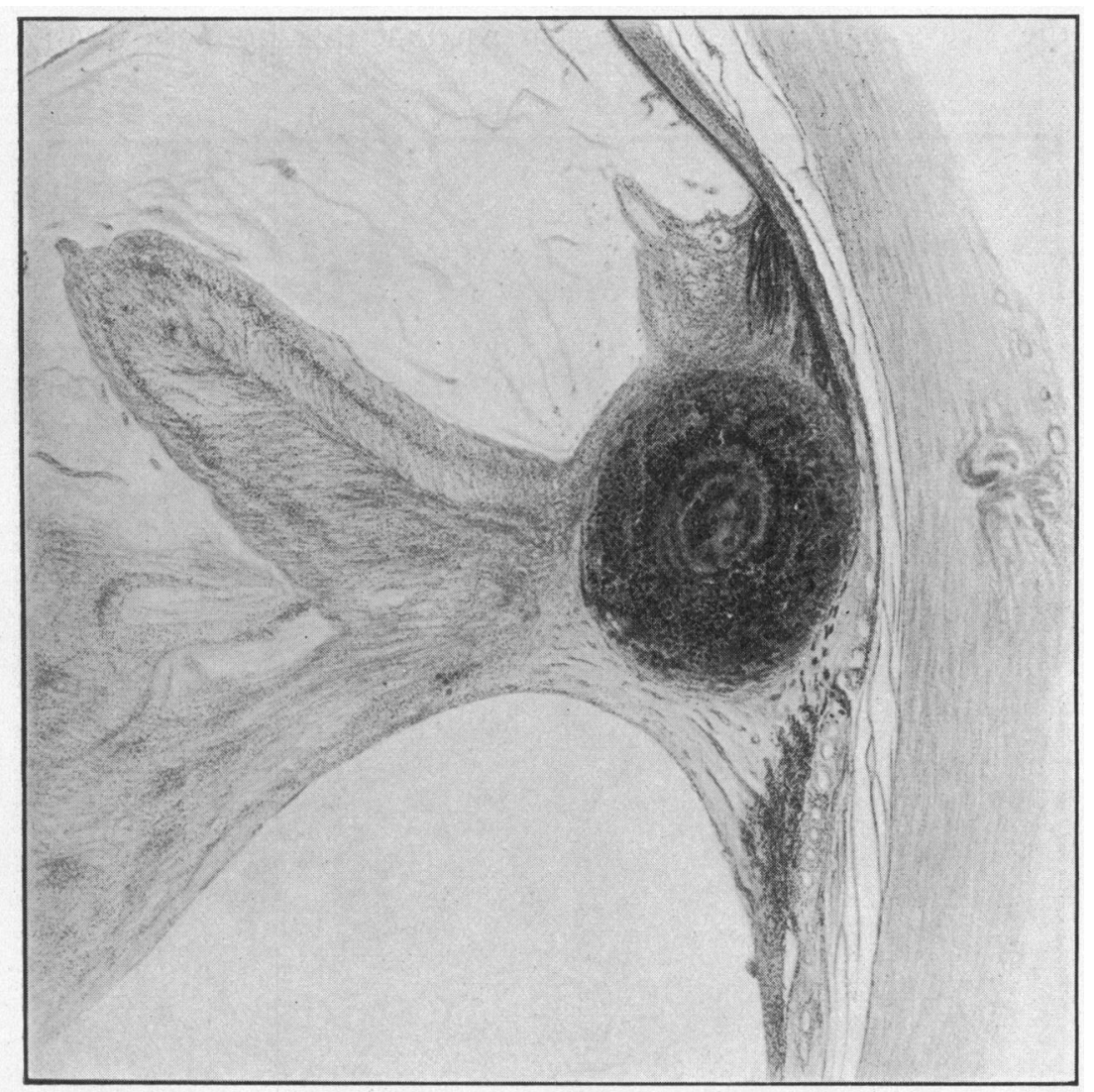

FIG. 5.

Temporal anterior part with fixation of the retina with nucleus of pigmented cells. See Fig. 3 .

Typical aspect of pseudo-glioma caused by congenital detachment. A ring of bone in the choroid around the optic nerve shows that the condition is an old one. The ciliary body shows no sign of so-called cyclitic membrane. This organ is imperfectly developed but shows otherwise nothing pathological. The retina is completely detached and appears stretched between its points of 
attachment, i.e., the entrance of the optic nerve and a zone well behind the ciliary body, thus forming a flower-shaped calyx. In the circular zone of attachment extremely marked pigmentation is found. (Fig. 5.) At one side this pigmentation is in the form of fan-shaped stripes or septa (Fig. 6), at the opposite side there exists, furthermore, a roundish mass of pigmented cells with a nucleus containing calcareous deposits. (Fig. 5.) By applying the Prussian blue test it was shown that this pigment did not

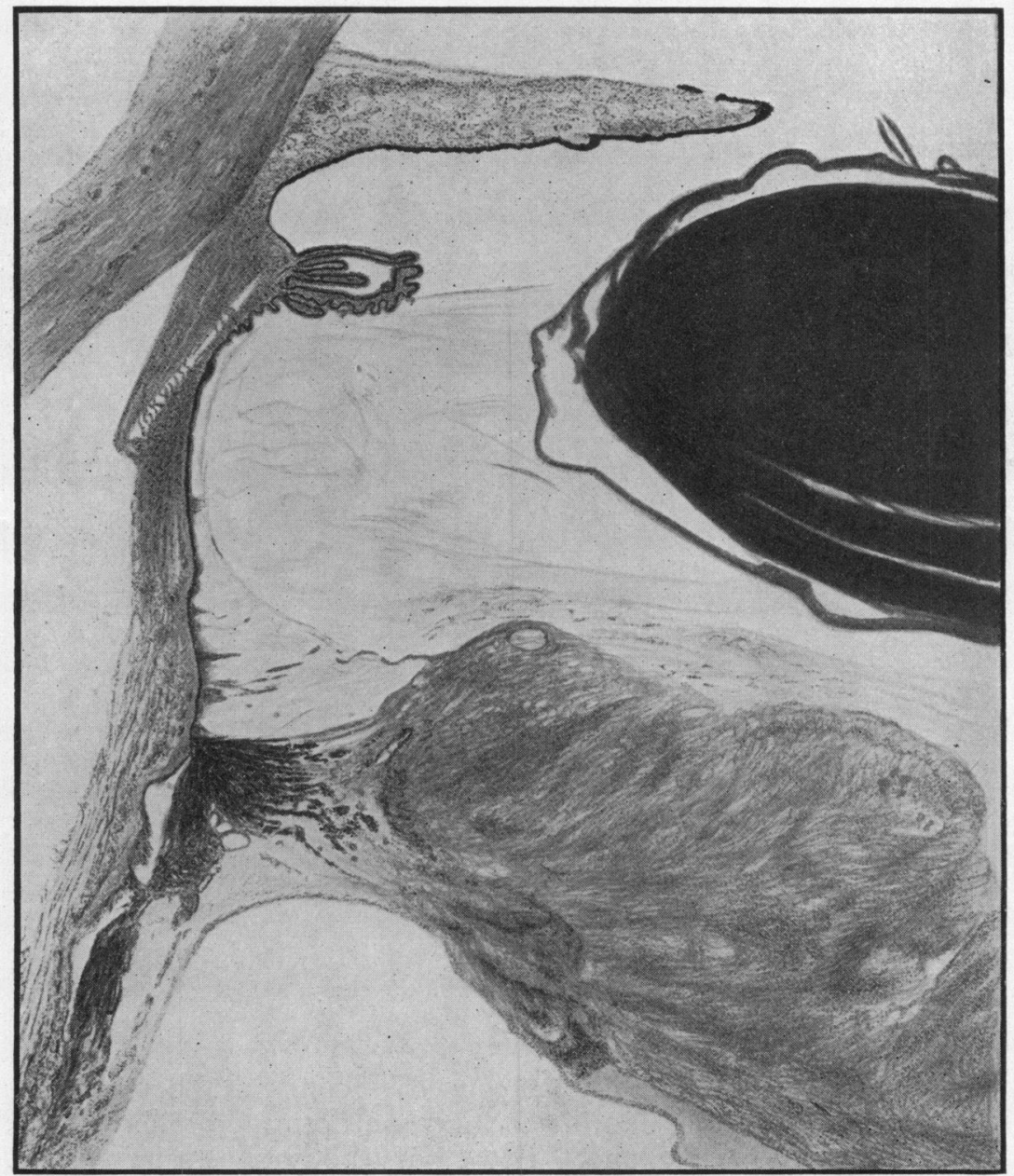

FIG. 6.

Nasal anterior part. See Fig. 3. 
contain iron and therefore was not of haemorrhagic origin. It seems that the optic nerve fibres with their vessels reach into the centre of the irregular septum formed by the remnants of the retina, whilst the stem of the calyx seems to be enclosed in enormous retinal cysts that are flattened against the nerve by traction. (Fig. 4.) In the pars plana of the ciliary body (or perhaps the retinal part of the ora serrata) cystoid degeneration (Iwanoff type) is found at one side. The vitreous shows no organisation but very clearly, "rests" of persistent embryonic vessels. The epithelium of the lens extends at both sides very far on to the posterior surface. Parts of the posterior cortex are cataractous, and here also cells (epithelium?) are found.

Nowhere are there signs of inflammation. The whole aspect is typical of a congenital detachment and resembles strongly the anatomical aspect of true cases of ablatio falciformis, showing thus once more the relation between both conditions that was already made sufficiently evident by the alternative occurrence of both conditions in the same families.

It may be pointed out that posterior synechiae, ectropion uveae and congenital obliteration of the angle of the anterior chamber are well-known signs of congenital developmental abnormalities and do not prove therefore an inflammatory origin.

The retina itself shows marked abnormality. Only here and there something resembling the normal retinal structure can be found. It would even be too much to say that the retinal layers are imperfectly differentiated. There exists in most parts a complete metaplasia with marked preponderance of the glial tissue. No rosette formation is visible. The figures show this condition better than a long description. I wish to point out specially that the optic nerve seems to be drawn well into the interior of the eye in exactly the same way as in cases of " retinal fold."

In the slides we could examine, nothing was found resembling abnormal tissue covering the retina and projecting in the direction of the optic nerve as described by Leber, who was of opinion that this proved an inflammatory origin resembling strongly the cases of detachment caused by mild forms of metastatic ophthalmia. (If this should be pathognomonic of an inflammatory origin, which nowadays is no longer accepted, then the complete absence of this tissue in our case should suggest here another origin.)

The choroid is extremely thin and shows only around the entrance of the optic nerve thickening with enclosure of bone. The pigment epithelium of the choroid is only partly visible, the parts of the choroid next to the optic nerve, especially the part where bone formation is visible, are totally devoid of pigment epithelium, 
whilst the development is very sparse and irregular in the equatorial parts. The strong development of pigment in the parts where the retina adheres to the choroid seems to be of retinal origin. (See the Fig.) In the ciliary part of the retina the pigment layer is well developed. The same is found in the iris.

The facts and arguments given above may be sufficient to prove the nature of the so-called ablatio falciformis congenita as a developmental abnormality. But as our knowledge is still imperfect, I think it advisable to describe every case that comes to our notice.

The following case shows many peculiarities that in itself justify a detailed description, the most interesting fact being that this case seems to be linked up with a somewhat atypical form of familial retinitis pigmentosa. Be it in an indirect way this once more suggests a developmental abnormality of familial and hereditary type.

Joh. H. L., aged ten years, from Eindhoven, visited our clinic in November, 1936. Since birth he showed rotatory nystagmus and the left eye was always blind. Signs of inflammation were never observed. The right eye has slightly sub-normal vision

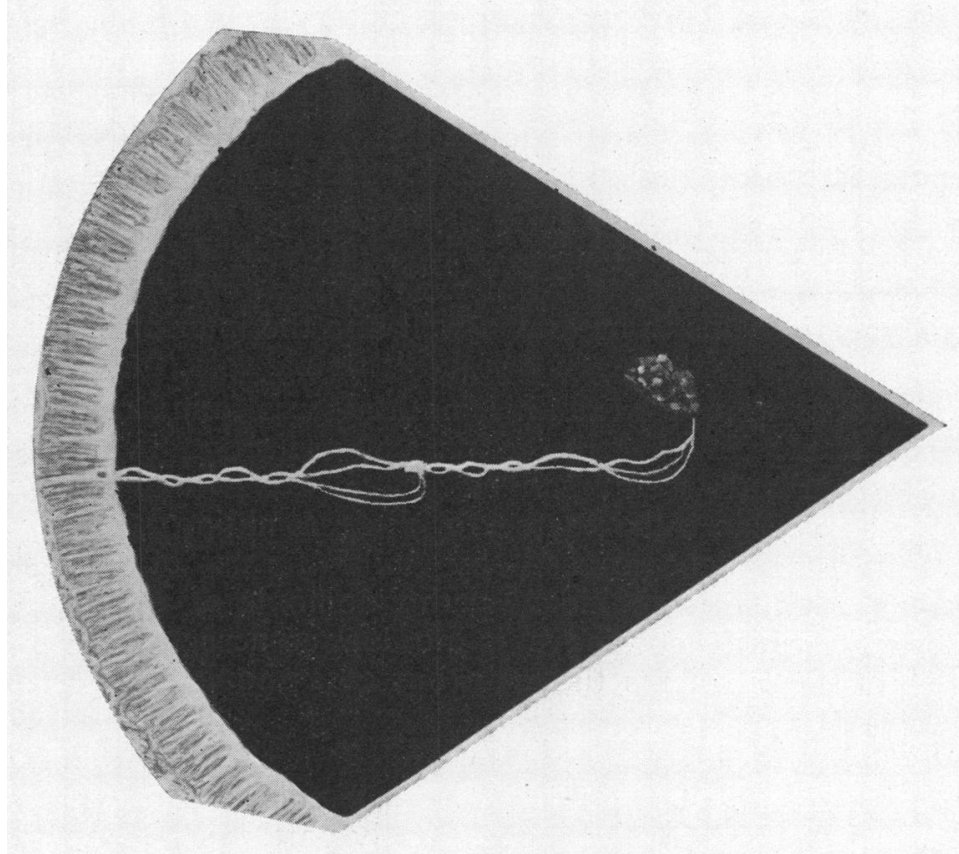

FIG. 9a.

Membrana pupillaris persistens. J. L. 


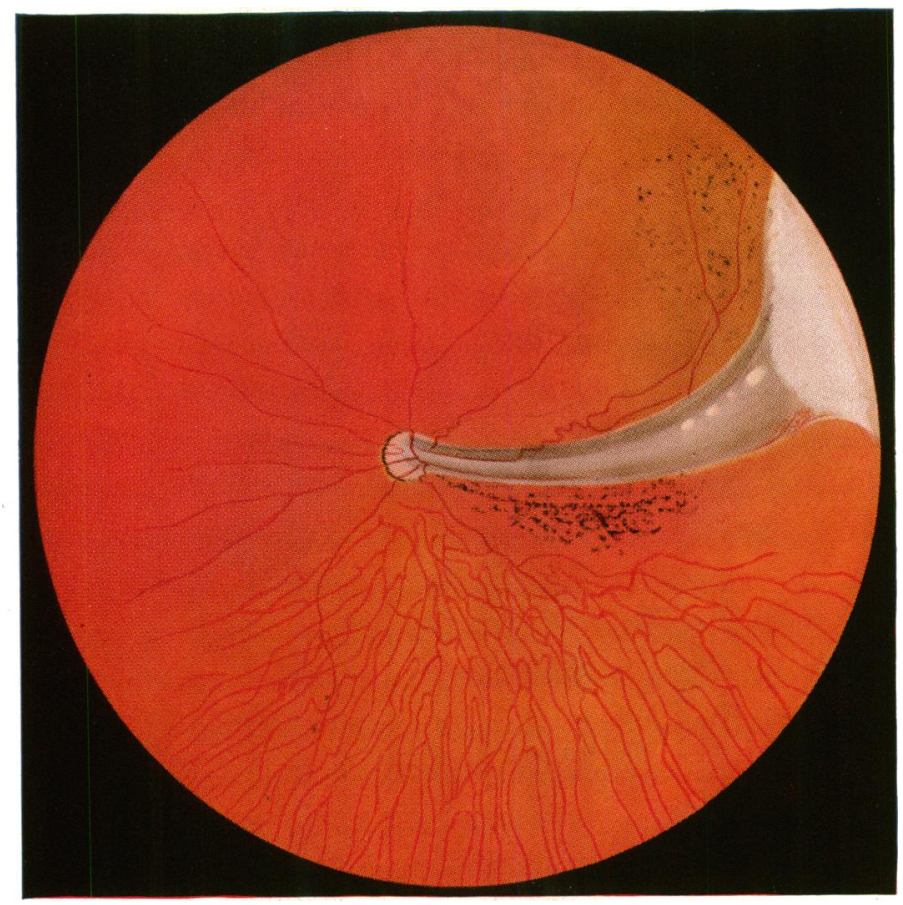

FIG. 2. 


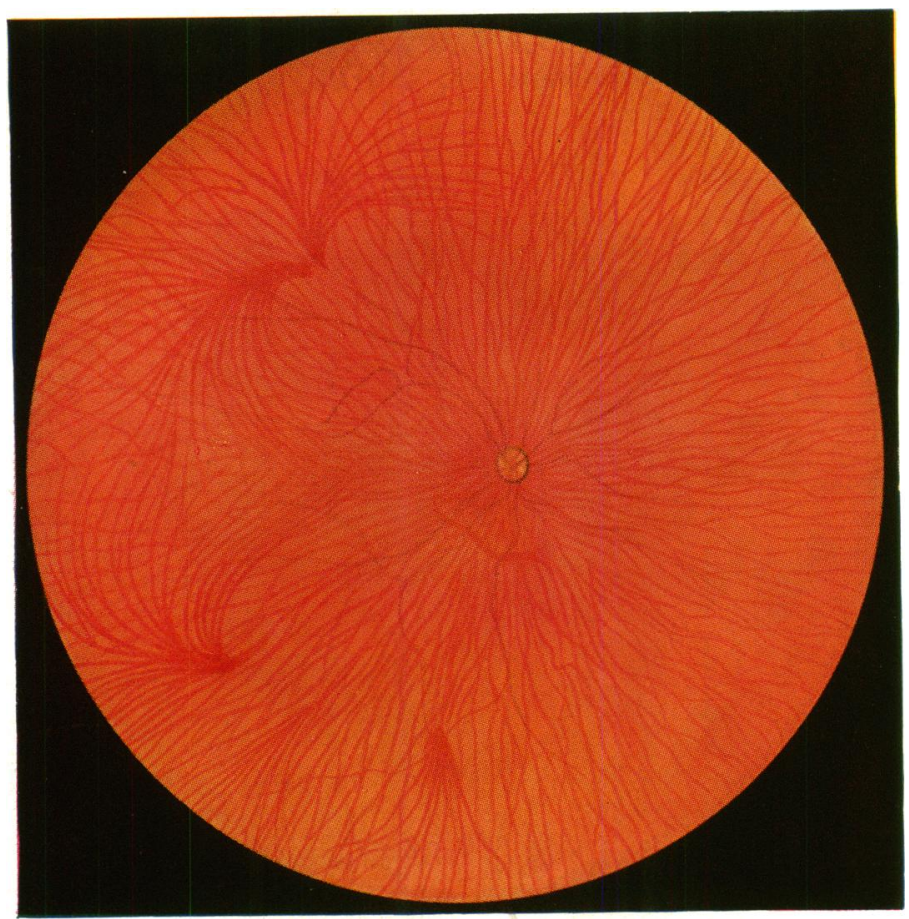

FIG. 8.

Pigment-free fundus of the right eye of the 10 years old J. L.

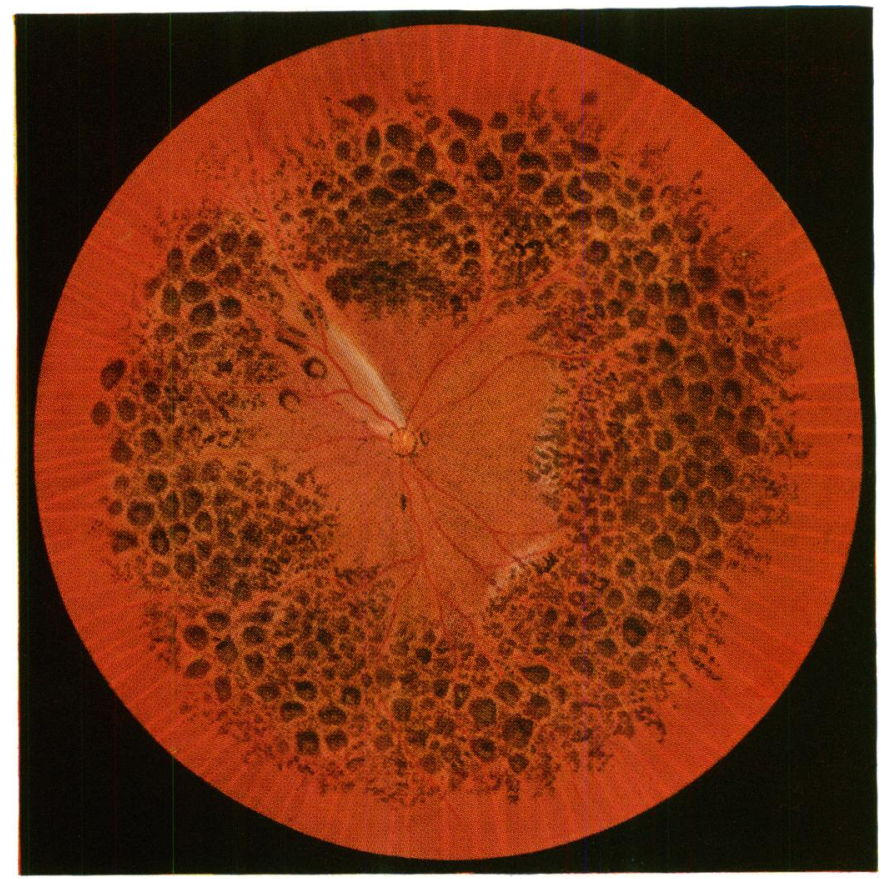

FIG. 10.

Fundus of the 70 years old grandmother L. B. with atrophia retinae pigmentosa and forme fruste of retinal fold. 
$(5 / 6)$. It is emmetropic. The fundus is nearly completely devoid of pigment, all the choroidal vessels being distinctly visible. The retinal vessels are extremely thin. Arteries and veins cannot be clearly distinguished. (Fig. 8.)

The left eye shows the following series of abnormalities :

1. Membrana pup. persistens. (Fig. 9a.)

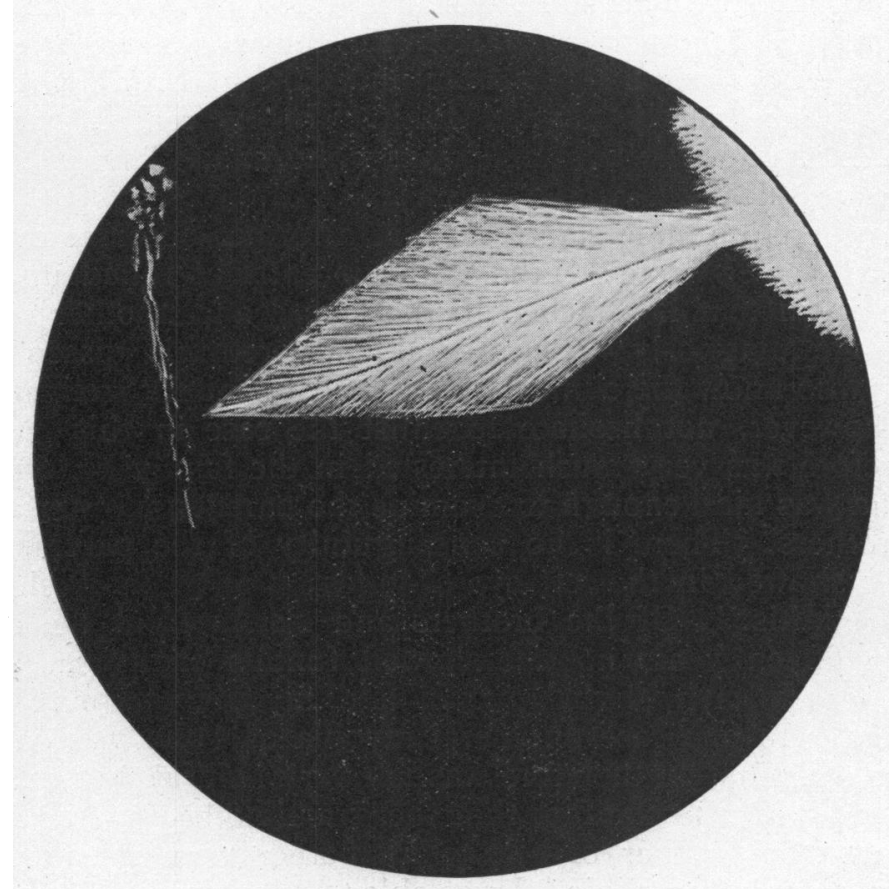

Fig. 9b.

Deposit at the posterior surface of the lens from which a feathershaped cataract emerges. J. L.

2. A deposit of (connective ?) tissue at the posterior surface of the lens in its nasal upper periphery. From this a feathershaped cataract emerges on the posterior surface of the lens pointing to the centre of the pupil. (Fig. 9b.)

3. Abnormal pigmentation in the pigment layer of the retina, partly in the form of dots of about the diameter of the optic disc, partly in the form of bows of pigmentation, partly in the form of finest pigmentations scattered between the bigger ones. Through and between all this pigmentation the choroidal vessels are very distinctly visible.

4. In the para-foveal parts and medially above the centre, 
yellowish white areas of depigmentation are visible, strongly resembling retinal colobomata or choroidal cicatrices.

5. A typical " retinal fold " running from the entrance of the optic nerve to the nasal superior periphery, where it is attached to the lens in the region of the tissue covering the posterior surface of the lens. (Fig. 7.)

On the surface of the fold three retinal vessels are to be seen emerging from it at some distance from the entrance of the optic nerve. At about $4 \mathrm{~mm}$. from the entrance of the optic nerve a single retinal vessel comes from under the fold running at some little distance nearly parallel to it. In its central parts this vessel is at one side bordered by a white line. This is the only visible vessel of the whole retina!

It is therefore understandable that a former observer overlooking this vessel wrote: " the retina is entirely rolled up into a single skein that is attached to the lens," and another observer made the diagnosis: "cicatricial chorioretinitis disseminata." Those who know the clinical aspect of congenital " retinal fold" will, however, not hesitate to enlist the case in this category. I therefore was very much interested in the family history. Dr. Ancona was kind enough to examine the parents, a sister and the six brothers. There is no consanguinity of the parents. The mother showed in the left eye changes described as " cicatricial chorioretinitis." Of the brothers and sisters from the ages of two to fifteen years no one showed fundus changes. Among the elder children slight myopia and myopic astigmatism was frequent. In one case unilateral myopia of 4.0D was observed.

This examination therefore was not very helpful, but our attention was drawn to the fact that the grandmother on the father's side and the brother of this grandmother were attended to in former years in our clinic. I was able to re-examine them with the following results :

The 70-years-old Mrs. L.B. was described in 1930 as a case of retinitis pigmentosa with complicated cataract. In 1931 lens extraction was performed on the left eye. It was then noticed that the pigmentation did not show the typical stellate shape but formed a broad ring of roundish dots, whilst the central parts of the retina were dusted by fine pigmentation. The blood vessels were fine. The field of vision was after operation about 20 to 30 degrees. The central vision was nearly $\frac{1}{2}$ after correction with a glass (+10.0D.sph.). The right eye was entirely amaurotic and had a cataracta subluxata. Ophthalmoscopic examination was impossible. At our examination the pigmentation corresponded quite well to the description given five years before, but on close examination something like a thin fold of the retina was also observed in the same axis as in the eye of the grandchild. (Fig. 10.) 
In order to have an unprejudiced opinion I asked our artist to sketch the fundus without drawing his attention to this foldlike appearance. The Figure (10) shows the result. In order to distinguish this somewhat uncommon retinitis pigmentosa from inflammatory alterations I also examined the brother of the grandmother.

W.A.B. (aged 58 years) showed in both eyes the picture reproduced here for the left eye. (Fig. 11.) The picture strongly

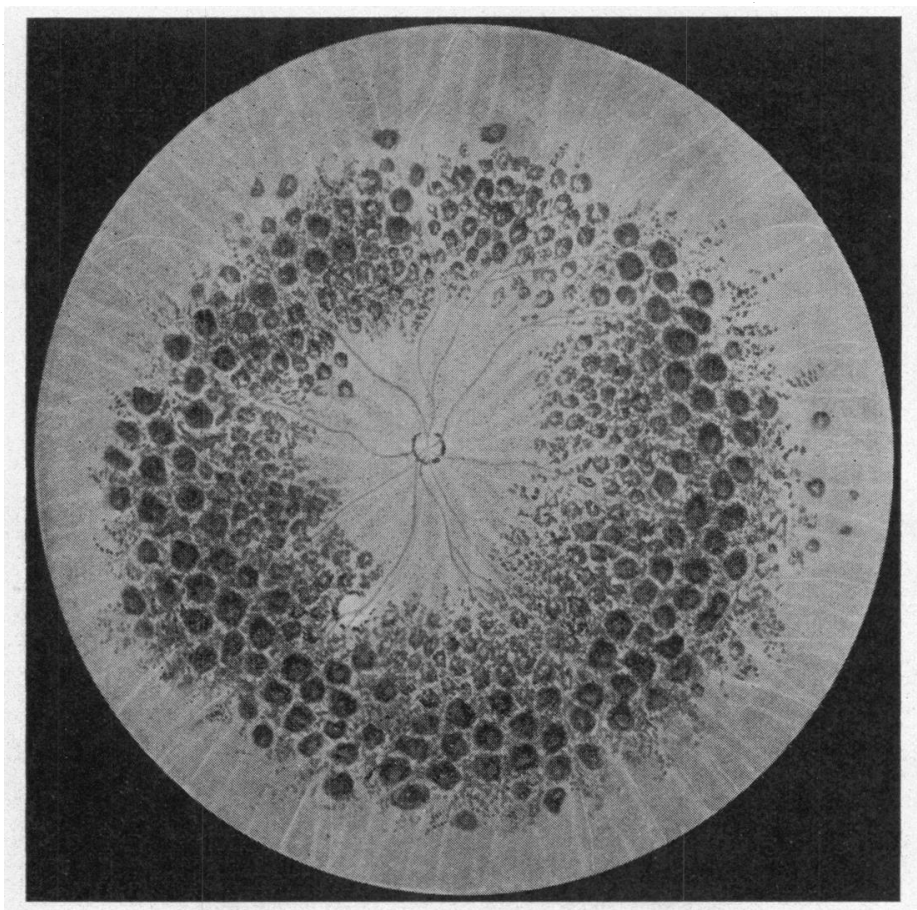

FIG. 11.

Fundus of the 58 years old brother of the grandmother W. B.

resembles that of his sister. The blood vessels are very fine, and beyond the zone of pigmentation are, without exception, changed into fine white lines. In the nasal inferior part just at the beginning of the zone of pigmentation a yellow patch resembling a cicatrix of chorioretinitis is visible. Both eyes show cataracta cort. post. Night blindness existed from early youth. The fields of vision are only 3 to 5 degrees, nevertheless the vision is $1 / 10$ in the right eye and $1 / 6$ in the left. Further information about the family was not available. 
It is to be regretted that at the moment of the examination of the ten-year-old child we did not examine the dark adaptation. The parents refused afterwards to re-visit the clinic for this purpose.

In discussing this case and especially the fundus alterations suggesting scars of chorioretinitis I might draw attention to similar cases described elsewhere, particularly to the case of Magnus (Graefe's Archiv., 118, 1920) who studied a case of bilateral pseudo-glioma caused by fibrous tissue behind the lens with arteria hyaloidea persistens and microphthalmos. The second eye could be partly examined ophthalmoscopically and the aspect is described as follows : discoloured and depigmentated areas are visible that remind one of choroiditis and are localised in the layer of the pigment epithelium. Nowhere retinal vessels were visible, although no detachment existed in this part !

This case shows that the fundus appearance found in our case does not necessarily prove an inflammatory process.

FURTHER LITERATURE

HEINE.-Arch. f. Ophthal., Bd. LVIII, 1904.

HEINE.-Zeitschr. f. Augenheilk., Bd. LI, 1923.

\title{
SOME CLINICAL NOTES ON THE NATURE OF THE RETINAL VENOUS PULSE
}

\author{
BY \\ N. PINES \\ LONDON
}

\section{Description}

THE same method was used as in the investigation of retinal vascular disease-a 12 volt red-free light worked with a current of 20 volts or more. This is essential as the brilliancy of the over-heated wire increases the red-free part of the spectrum and the more overcharged the lamp the better it is for the resulting illumination. The patient would generally experience great discomfort if this intense light were to fall unguarded on to the retina, but if the red-free filter is placed in such a position that all the light emanating from the bulb is coloured, it will mitigate this inconvenience.

Commencing from the periphery, in the primary branches of the veins and, in favourable cases, in even the secondary branches, especially the thicker ones, the venous pulse was discovered in all patients except where an obstruction in the optic nerve or further beyond it produced an engorgement of the veins. It is much 